\title{
SCIENTIFIC REPORTS

\section{OPEN Metal-organic framework-derived metal oxide nanoparticles@reduced graphene oxide composites as cathode materials for rechargeable aluminium-ion batteries}

\author{
Kaiqiang Zhang ${ }^{1,2}$, Tae Hyung Lee ${ }^{1}$, Joo Hwan Cha ${ }^{3}$, Ho Won Jang $\mathbb{D}^{1}$, Ji-Won Choi ${ }^{2}$, \\ Morteza Mahmoudi ${ }^{4}$ \& Mohammadreza Shokouhimehr $\mathbb{1}^{1,4}$
}

The use of metal oxides as electrode materials has seen great success in lithium-ion batteries. However, this type of electrode materials has been regarded as an improper option for rechargeable aluminiumion batteries (AIBs) in comparison with sulfides and selenides, and has, thus, been nearly abandoned. Here, we demonstrate the suitability of metal oxides as cathode materials of AIBs, exhibiting high electrochemical activities toward Al-ion storage. We designed economical metal-oxide cathodes $\left(\mathrm{CO}_{3} \mathrm{O}_{4} @\right.$ @reduced graphene oxide ( $\left.\mathrm{rGO}\right), \mathrm{Fe}_{2} \mathrm{O}_{3} @ r G O$, and $\mathrm{CoFe}_{2} \mathrm{O}_{4} @ \mathrm{rGO}$ ) for AIBs. The $\mathrm{Co}_{3} \mathrm{O}_{4} @ \mathrm{rGO}$ displayed superior electrochemical properties, regarding both capacity and lifespan, to the current state-of-the-art cathode material reported by scientific literature. Furthermore, the $\mathrm{CoFe}_{2} \mathrm{O}_{4} @ \mathrm{gGO}$ exhibits rational electrochemical capacities and an extremely stable charge/discharge process with an excellent Coulombic efficiency of $99.6 \%$. The proposed study expects to stimulate researchers to focus on the overlooked metal oxides as competitive cathode materials for high performance AIBs.

With the ever-growing environmental problems and ever-declining storage amounts of fossil energy resources, methods of integrating green and sustainable energy resources (such as solar, tidal, and wind energies) into an electric grid have been intensively researched ${ }^{1-6}$. However, a common issue for natural energy resources is the intermittency, which requires the employment of intermediate high-performing and cost-efficient energy storage devices $^{7}$. Aluminium-ion batteries (AIBs), as post-lithium-ion batteries, are regarded as potential candidates for the next generation of electric energy storage, owing to the uniquely high charge density $\left(\mathrm{Al}^{3+}\right)$ and rich substantial reserves in the earth $\left(\sim 8000 \mathrm{ppm},<2.5 \$ \mathrm{~kg}^{-1}\right)^{8}$. After the significant advance on AIBs made by Dai's group ${ }^{9}$, an intensive study on AIBs has been performed, focusing on the development of the cathode materials as an $\mathrm{Al}$ metal can be used directly as an anode and the employment of ionic-liquid electrolyte ([EMIM]Cl/ $\mathrm{AlCl}_{3}$ ) enables stable $\mathrm{Al}$ stripping and plating in AIBs. Reliable cathode materials for AIBs which can tolerate the high charge density $\left(\mathrm{Al}^{3+}\right)$ and large ionic radius of the inserted ion $\left(\mathrm{AlCl}_{4}^{-}\right)$are important for high-performing AIBs ${ }^{10}$. To meet this requirement, research groups have intensively explored C-based materials (e.g., defect-free graphene, three-dimensional graphene foam, and natural graphite) among other compounds (e.g., sulfides and selenides $)^{11-14}$. Studies on the metal-oxide compounds as cathode materials of AIBs assembled with an ionic-liquid electrolyte are rare due to the high electronegativity of $\mathrm{O}$ ions. Metal oxides, such as $\mathrm{TiO}_{2}$ and $\mathrm{MoO}_{3}$, are initially demonstrated to be decent cathode materials in aqueous $\mathrm{AIBs}^{15,16}$. However, further investigation on metal oxides as the cathode materials of non-aqueous AIBs has been overlooked, except a few relevant reports ${ }^{17,18}$ with inferior electrochemical capacities and limited lifespan. Zhang's group designed $\mathrm{CuO}$ microsphere architectures for use

\footnotetext{
${ }^{1}$ Department of Materials Science and Engineering, Research Institute of Advanced Materials, Seoul National University, Seoul, 08826, Republic of Korea. ${ }^{2}$ Electronic Materials Center, Korea Institute of Science and Technology (KIST), Seoul, 136-791, Republic of Korea. ${ }^{3}$ Innovative Enterprise Cooperation Center, Korea Institute of Science and Technology (KIST), Seoul, Republic of Korea. 'Precision Health Program, Michigan State University, East Lansing, MI, 48823, USA. Correspondence and requests for materials should be addressed to J.-W.C. (email: jwchoi@kist.re.kr) or M.M. (email: Mahmou22@msu.edu) or M.S. (email:mrsh2@snu.ac.kr)
} 


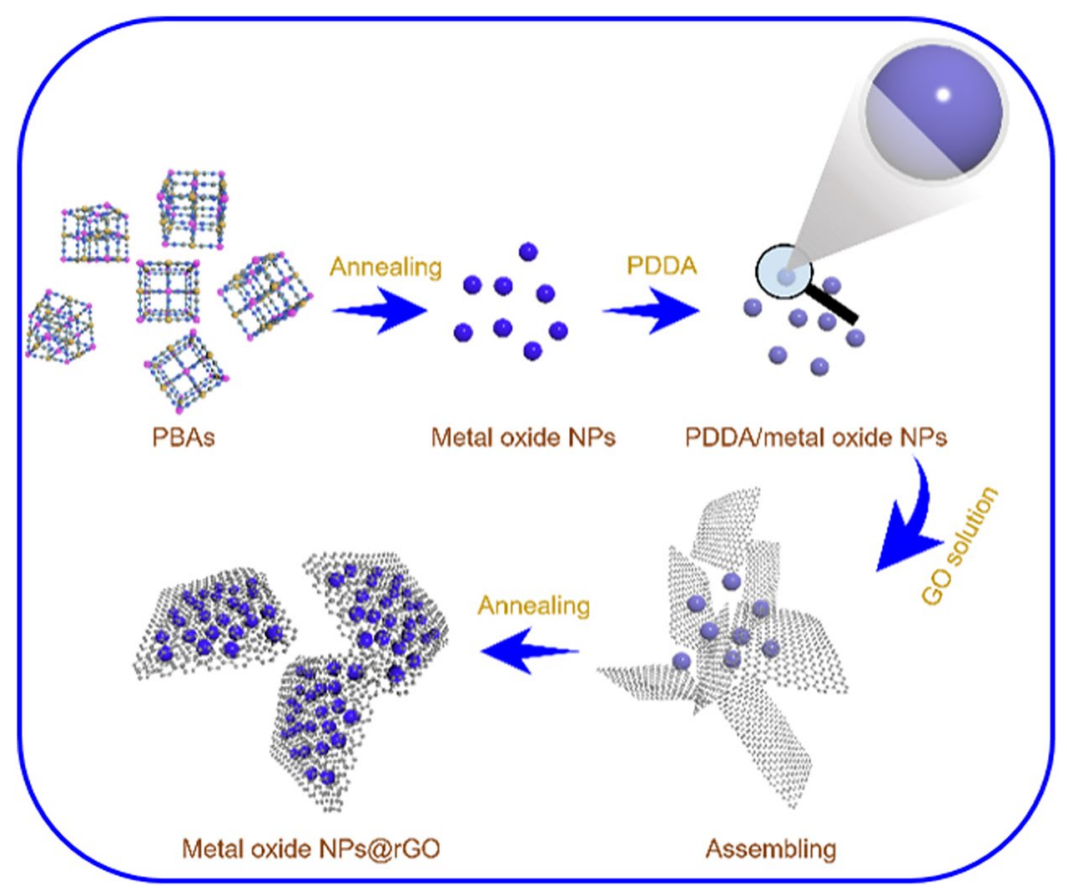

Figure 1. Schematic illustration of the synthesis process of metal-oxide NPs@rGO.

as a cathode material of AIBs, demonstrating a rational initial capacity $\left(\sim 250 \mathrm{mAh} \mathrm{g}^{-1}\right)$ but a rapid decay $(\sim 100$ $\mathrm{mAh} \mathrm{g}^{-1}$ at the $100^{\text {th }}$ cycle) at a charge/discharge current density of $200 \mathrm{~mA} \mathrm{~g}^{-119}$. Their findings, thus, inspire us to conduct an in-depth study on this issue.

Metal-organic frameworks (MOFs) have been demonstrated to be a novel class of original or sacrificial materials for multiple applications, including gas absorption, supercapacitors, and batteries, owing to their porous structures and high surface areas $\mathrm{s}^{20-22}$. The MOFs derived porous and organized electrode materials provide more exposed active sites, short diffusion length, and integrity of the electrode materials during electrochemical reactions. Zhang et al. demonstrated porous $\mathrm{CuO} / \mathrm{Cu}_{2} \mathrm{O}$ as a high-performance anode material for sodium-ion batteries, exhibiting a reversible capacity of $415 \mathrm{mAh} \mathrm{g}^{-1}$ at $50 \mathrm{mAg}^{-123}$. Furthermore, Zou et al. reported Ni-based MOF-derived $\mathrm{NiO} / \mathrm{Ni}$ nanocrystals as an advanced anode material of lithium-ion batteries, showing an excellent reversible capacity $\left(1144 \mathrm{mAh} \mathrm{g}^{-1}\right)$, cyclability, and rate performance ${ }^{24}$. Recently, Xu et al. used an MOF as a precursor to form carbon-encapsulated selenides as superior anode materials for sodium-ion batteries, with a potential electrochemical property of $218 \mathrm{mAh} \mathrm{g}^{-1}$ after 500 cycles at a current density of $3,000 \mathrm{~mA} \mathrm{~g}^{-125}$. However, reports on MOF-derived metal oxides as cathode materials for AIBs are absent. It is, thus, highly interesting to further study the electrochemical properties of MOF-derived metal oxides as cathode materials for AIBs.

Herein, we demonstrate the advanced electrochemical properties of unit and multiple metal oxides $\left(\mathrm{Co}_{3} \mathrm{O}_{4} @\right.$ reduced graphene oxide ( $\mathrm{rGO}), \mathrm{Fe}_{2} \mathrm{O}_{3} @ \mathrm{rGO}$, and $\mathrm{CoFe}_{2} \mathrm{O}_{3} @ \mathrm{rGO}$ ) as cathode materials of AIBs, in which the rGO is employed as a wrapping layer to reinforce the material structures. Prussian blue analog (PBA)-type MOF $\left(\mathrm{CoCo}(\mathrm{CN})_{6}, \mathrm{FeFe}(\mathrm{CN})_{6}\right.$, and $\left.\mathrm{FeCo}(\mathrm{CN})_{6}\right)$ are employed as the precursors, which can be constructed by a facile co-precipitation process in an aqueous bath without further hydrothermal treatment. It is found that the synthesized metal-oxide samples exhibit superior electrochemical properties as cathode materials for AIBs.

\section{Results and Discussion}

The synthesis process is illustrated in Fig. 1. The entire process is performed in an aqueous bath and could be easily mass produced. The morphologies of the prepared $\mathrm{Co}_{3} \mathrm{O}_{4} @ \mathrm{rGO}, \mathrm{Fe}_{2} \mathrm{O}_{3} @ \mathrm{rGO}$, and $\mathrm{CoFe}_{2} \mathrm{O}_{4} @ \mathrm{rGO}$ depicted in Fig. 2 and Supplementary Figs S1-S4 are observed using scanning electron microscopy (SEM) and transmission electron microscopy (TEM). The rGO wrapping layer is clearly observed in the scanning TEM (STEM, Fig. 2a,d), where almost-transparent graphene sheets are exhibited. Such a phenomenon can be reconfirmed by the TEM morphologies (Fig. 2b,f). The consistent elements of the final $\mathrm{Co}_{3} \mathrm{O}_{4} @ \mathrm{rGO}, \mathrm{Fe}_{2} \mathrm{O}_{3} @ \mathrm{rGO}$ and $\mathrm{CoFe}_{2} \mathrm{O} @ \mathrm{rGO}$ are further qualitatively measured by energy-dispersive X-ray spectroscopy (EDX) (Fig. 2a,e), where the component elements are uniformly distributed over-through each particle.

The same structural and elemental information can also be obtained for $\mathrm{Fe}_{2} \mathrm{O}_{3} @ \mathrm{rGO}$ (Supplementary Fig. S1), which is similar to that of $\mathrm{Co}_{3} \mathrm{O}_{4} @ \mathrm{rGO}$ and $\mathrm{CoFe}_{2} \mathrm{O}_{4} @ \mathrm{rGO}$, displaying clear pocket-like rGO-wrapped metal-oxide nanoparticles (NPs) (Supplementary Figs S1-S4). The elemental characteristics for the three types of material are further studied with an electron probe microanalyser (EPMA), as shown in Supplementary Fig. S5. The aligned atoms in the high-resolution TEM (HRTEM) and the corresponding fast Fourier transform diffraction patterns depict well-crystallized natures for $\mathrm{Co}_{3} \mathrm{O}_{4} @ \mathrm{rGO}, \mathrm{Fe}_{2} \mathrm{O}_{3} @ \mathrm{rGO}$, and $\mathrm{CoFe}_{2} \mathrm{O}_{4} @ \mathrm{rGO}$ (Fig. 2c,g and Supplementary Fig. S4). The interplanar spacing of $\mathrm{Co}_{3} \mathrm{O}_{4} @ \mathrm{rGO}, \mathrm{Fe}_{2} \mathrm{O}_{3} @ \mathrm{rGO}$, and $\mathrm{CoFe}_{2} \mathrm{O}_{4} @ \mathrm{rGO}$ measured using HRTEM are $0.58,0.37$, and $0.45 \mathrm{~nm}$, respectively. 


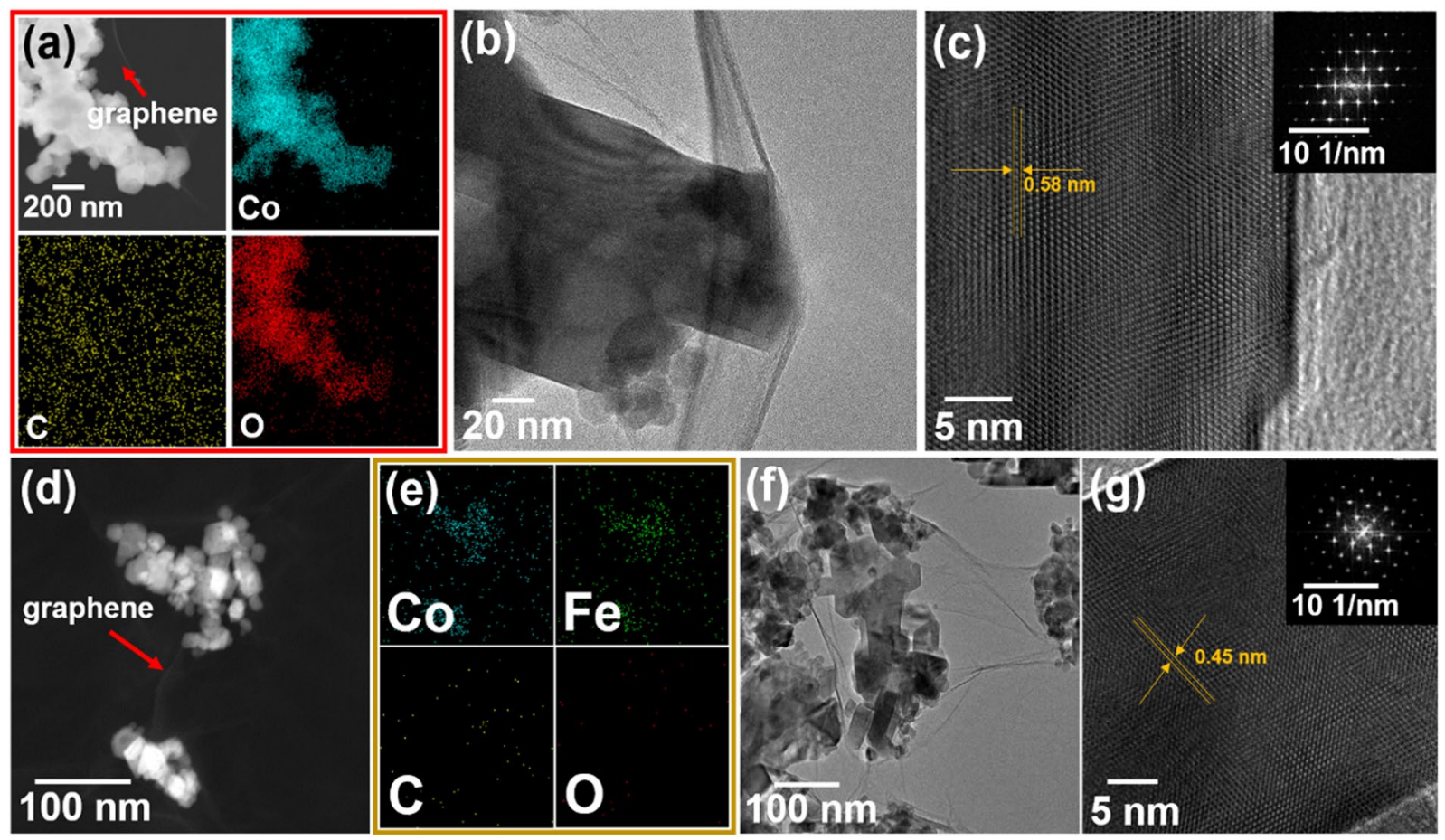

Figure 2. (a) STEM and EDX mapping, (b) TEM, and (c) HRTEM images of $\mathrm{Co}_{3} \mathrm{O}_{4} @ \mathrm{rGO}$. (d) STEM, (e) EDX mapping, (f) TEM, and (g) HRTEM images of $\mathrm{CoFe}_{2} \mathrm{O}_{4} @ \mathrm{rGO}$.

The structures of $\mathrm{Co}_{3} \mathrm{O}_{4} @ \mathrm{rGO}, \mathrm{Fe}_{2} \mathrm{O}_{3} @ \mathrm{rGO}$, and $\mathrm{CoFe}_{2} \mathrm{O}_{4} @ \mathrm{rGO}$ are observed via X-ray diffraction (XRD) following a contrastive analysis. After facile heat treatments for the pre-prepared PBAs, $\mathrm{Co}_{3} \mathrm{O}_{4}, \mathrm{Fe}_{2} \mathrm{O}_{3}$, and $\mathrm{CoFe}_{2} \mathrm{O}_{4}$ are formed based on the well-indexed diffraction peaks, which can be preserved after the introduction of rGO (Fig. 3). The XRD results of $\mathrm{Co}_{3} \mathrm{O}_{4} @ \mathrm{rGO}, \mathrm{Fe}_{2} \mathrm{O}_{3} @ \mathrm{rGO}$, and $\mathrm{CoFe}_{2} \mathrm{O}_{4} @ \mathrm{rGO}$ exhibit combined phases of metal-oxide and rGO (humps at $\sim 20^{\circ}$ ). The introduced protective layer (rGO) is further detected with Raman spectroscopy, as shown in Fig. 3d-f, and the characteristic D and G bands are the same as naked rGO (Supplementary Fig. S6). This indicates well-preserved graphene layers after the self-assembly process in aqueous solutions and annealing processes. The metal-oxide phases in the as-prepared $\mathrm{Co}_{3} \mathrm{O}_{4} @ \mathrm{rGO}, \mathrm{Fe}_{2} \mathrm{O}_{3} @ \mathrm{rGO}$, and $\mathrm{CoFe}_{2} \mathrm{O}_{4} @ \mathrm{rGO}$ are further detected with X-ray photoelectron spectroscopy (XPS, Fig. 4). Co-existing $\mathrm{Co}^{2+}$ and $\mathrm{Co}^{3+}$ for $\mathrm{Co}_{3} \mathrm{O}_{4} @ \mathrm{rGO} ; \mathrm{Fe}^{3+}$ for $\mathrm{Fe}_{2} \mathrm{O}_{3} @ \mathrm{rGO}$; $\mathrm{Co}^{2+}$ and $\mathrm{Fe}^{3+}$ for $\mathrm{CoFe}_{2} \mathrm{O}_{4} @ \mathrm{rGO}$ are analysed, which indirectly demonstrate the phase results obtained from the XRD spectra. Meanwhile, a wide survey of the XPS spectra for the three samples (Supplementary Fig. S7) further demonstrates the bonding natures; similar and single deconvoluted diffraction peaks with high intensities are observed for $\mathrm{C} 1 \mathrm{~s}$, revealing the single-existence state of the rGO in samples. Furthermore, three deconvoluted O 1s peaks (Supplementary Fig. S6c,f,i) correspond to the metal oxide and absorbed water molecules in each sample, with a slight difference in peak intensities.

The thermal stabilities of the as-prepared samples were measured via thermogravimetric analysis (TGA) prior to the electrochemical measurements. Sufficient thermal stabilities until $400^{\circ} \mathrm{C}$ for the samples are verified (Supplementary Fig. S8), with less absorbed water species. For the sake of the subsequent electrochemical measurements, the mixture ratios of the three types of materials are measured using X-ray fluorescence (XRF). Besides the qualitative characteristic elemental curves (Supplementary Fig. S9), the metal-oxide NPs/rGO ratios are shown to be 49:51 for $\mathrm{Co}_{3} \mathrm{O}_{4} @ \mathrm{rGO}, 62: 38$ for $\mathrm{Fe}_{2} \mathrm{O}_{3} @ \mathrm{rGO}$, and 40:60 for $\mathrm{CoFe}_{2} \mathrm{O}_{4} @ \mathrm{rGO}$ (Supplementary Table S1). The obtained results are used as reference values for calculations of the subsequent current densities and specific capacities.

Electrochemically active voltage ranges of the three cathode materials are diagnosed using cyclic voltammetry (CV) curves from $0.05-2.2 \mathrm{~V}$ vs. $\mathrm{AlCl}_{4}^{-} / \mathrm{Al}$, as shown in Fig. 5, where the redox peaks can be clearly observed for each sample. In particular, two pairs of reduction/oxidation peaks at $\sim 0.5 / 0.8$ and $0.9 / 1.3 \mathrm{~V} \mathrm{vs.} \mathrm{AlCl}_{4}{ }^{-} / \mathrm{Al} \mathrm{for}^{-}$ $\mathrm{Co}_{3} \mathrm{O}_{4} @ \mathrm{rGO}, \sim 0.25 / 0.70$ and 1.8/2.0 V vs. $\mathrm{AlCl}_{4}{ }^{-} / \mathrm{Al}$ for $\mathrm{Fe}_{2} \mathrm{O}_{3} @ \mathrm{rGO}$, and $\sim 0.3 / 0.8$ and 1.8/2.0 V vs. $\mathrm{AlCl}_{4}{ }^{-} / \mathrm{Al}$ for $\mathrm{CoFe}_{2} \mathrm{O}_{4} @ \mathrm{rGO}$ are displayed, demonstrating the typical electrochemical-based charge/discharge processes. Furthermore, stage by stage charge/discharge processes are demonstrated by these multiple peaks. We, thus, discharge the electrodes comprising of the as-prepared products to 0.2 and $0.7 \mathrm{~V}$ vs. $\mathrm{AlCl}_{4}{ }^{-} / \mathrm{Al}$ for $\mathrm{Co}_{3} \mathrm{O}_{4} @ \mathrm{rGO}$; 0.1, 0.5, and 1.5 V vs. $\mathrm{AlCl}_{4}{ }^{-} / \mathrm{Al}$ for $\mathrm{Fe}_{2} \mathrm{O}_{3} @ \mathrm{rGO} ; 0.1,0.5$, and $1.5 \mathrm{~V}$ vs. $\mathrm{AlCl}_{4}{ }^{-} / \mathrm{Al}$ for $\mathrm{CoFe}_{2} \mathrm{O}_{4} @ \mathrm{rGO}$ to reveal the underlying electrochemical reactions. For which, it is necessary to know how much $\mathrm{Al}$ species is inserted in the products in each stage. One facile solution is the EDX mapping ${ }^{7}$. By which, the inserted $\mathrm{Al}$ species amount increases with discharge going deeper for all products as recorded in Supplementary Tables S2-S4 where the ratios of $\mathrm{Co} / \mathrm{Al}$ for $\mathrm{Co}_{3} \mathrm{O}_{4} @ \mathrm{rGO}, \mathrm{Fe} / \mathrm{Al}$ for $\mathrm{Fe}_{2} \mathrm{O}_{3} @ \mathrm{rGO}$, and $\mathrm{Fe}$ (or $\mathrm{Co}$ )/Al for $\mathrm{CoFe}_{2} \mathrm{O}_{4} @ \mathrm{rGO}$ are gradually enhanced. Furthermore, the effective electrochemical reaction for each stage can be roughly concluded as follows. The same electrochemical reaction in the anode side can be obtained in different electrochemical stages 

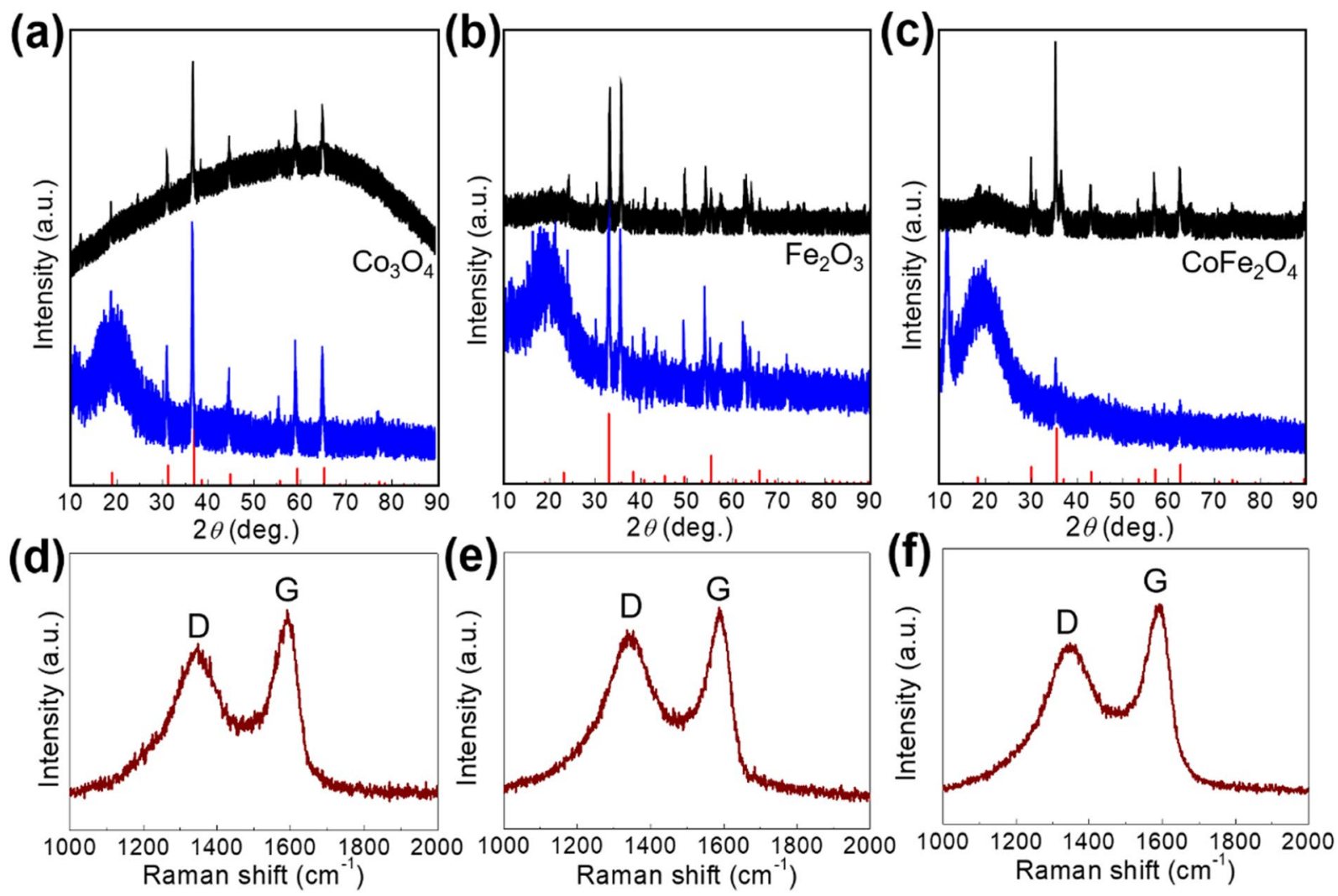

Figure 3. $\mathrm{XRD}$ peaks of (a) $\mathrm{Co}_{3} \mathrm{O}_{4}$ and $\mathrm{Co}_{3} \mathrm{O}_{4} @ \mathrm{rGO}$, (b) $\mathrm{Fe}_{2} \mathrm{O}_{3}$ and $\mathrm{Fe}_{2} \mathrm{O}_{3} @ \mathrm{rGO}$, and (c) $\mathrm{CoFe}_{2} \mathrm{O}_{4}$ and $\mathrm{CoFe}_{2} \mathrm{O}_{4} @ \mathrm{rGO}$. Raman spectra of (d) $\mathrm{Co}_{3} \mathrm{O}_{4} @ \mathrm{rGO},(\mathbf{e}) \mathrm{Fe}_{2} \mathrm{O}_{3} @ \mathrm{rGO}$, and (f) $\mathrm{CoFe}_{2} \mathrm{O}_{4} @ \mathrm{rGO}$.
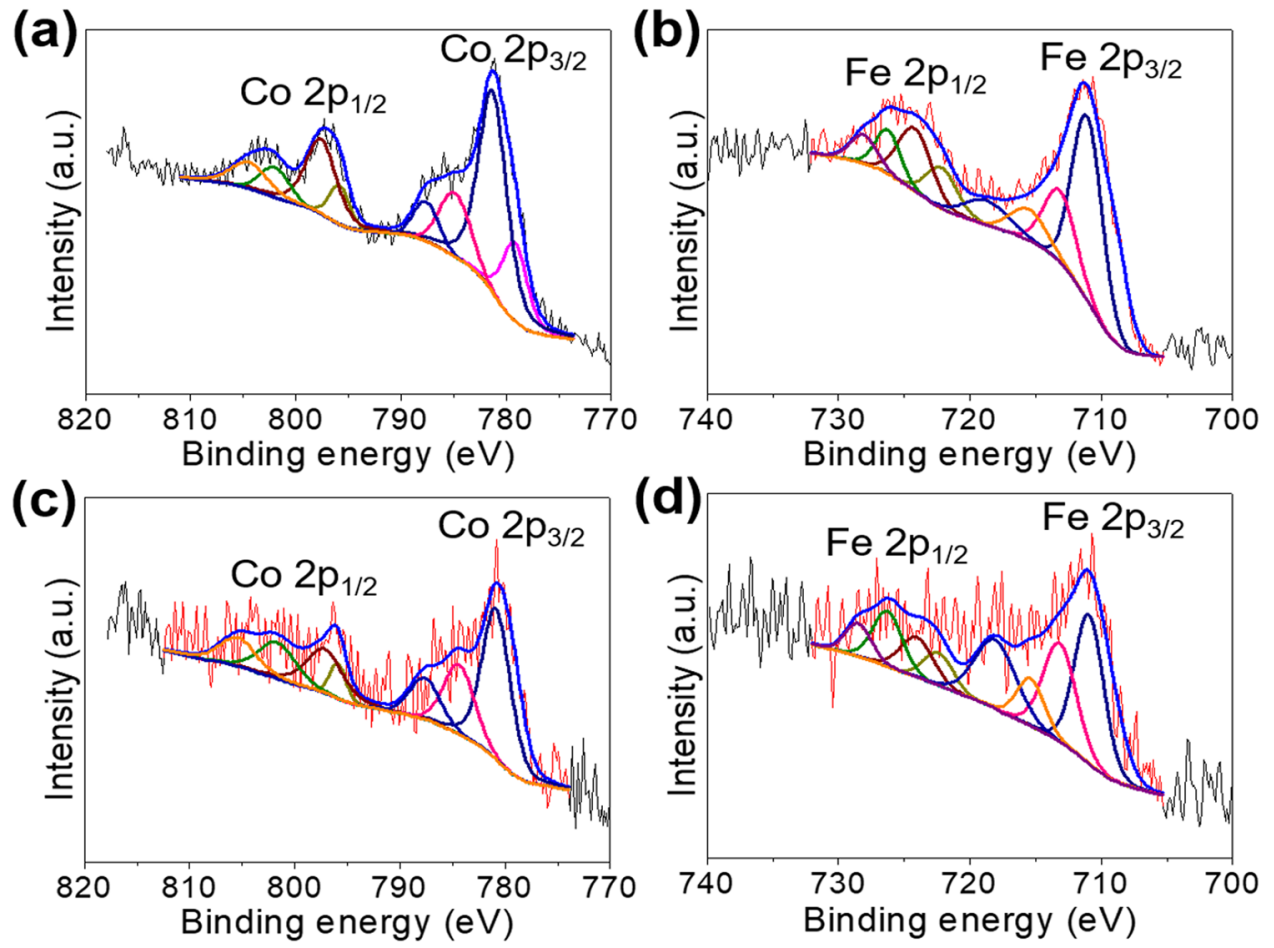

Figure 4. XPS spectra of (a) Co $2 \mathrm{p}$ of the $\mathrm{Co}_{3} \mathrm{O}_{4} @ \mathrm{rGO},(\mathbf{b}) \mathrm{Fe} 2 \mathrm{p}$ of the $\mathrm{Fe}_{2} \mathrm{O}_{3} @ \mathrm{rGO}$, and (c) Co $2 \mathrm{p}$ and (d) $\mathrm{Fe}$ $2 \mathrm{p}$ of the $\mathrm{CoFe}_{2} \mathrm{O}_{4} @ \mathrm{rGO}$. 

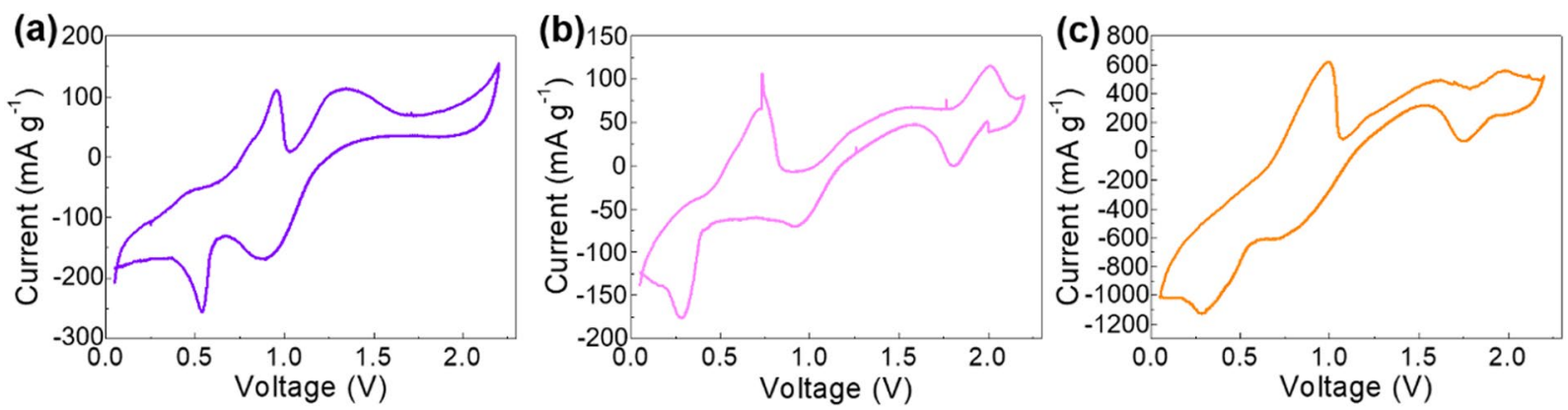

Figure 5. CV curves of (a) $\mathrm{Co}_{3} \mathrm{O}_{4} @ \mathrm{rGO},(\mathbf{b}) \mathrm{Fe}_{2} \mathrm{O}_{3} @ \mathrm{rGO}$, and (c) $\mathrm{CoFe}_{2} \mathrm{O}_{4} @ \mathrm{rGO}$ from $0.05-2.2 \mathrm{~V}$ vs. $\mathrm{AlCl}_{4}{ }^{-} /$ Al.

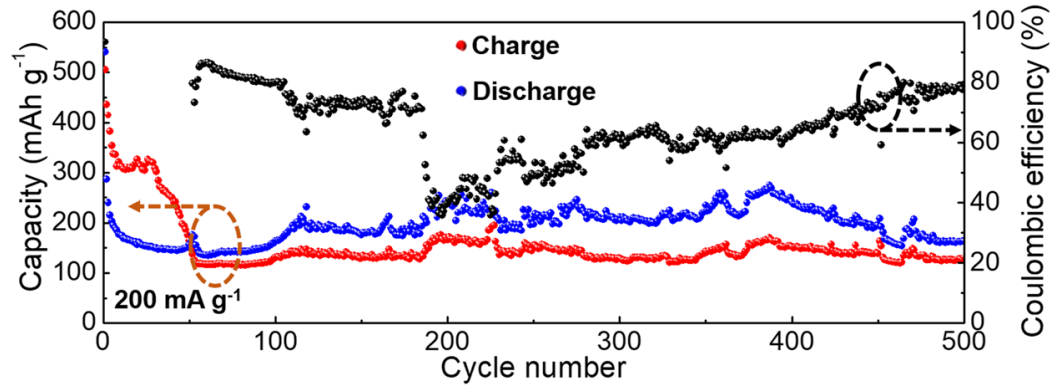

Figure 6. Repeated charge/discharge cycling measurement for the $\mathrm{Co}_{3} \mathrm{O}_{4} @ \mathrm{rGO}$ at $200 \mathrm{mAg}^{-1}$.

(Supplementary Eqs S1, S2) ${ }^{17,18}$. In the cathode side, discharge proceeds stage by stage by following the corresponding electrochemical reactions (Supplementary Eqs S3-S10). Al species is inserted into the discharge product formed in the last discharge stage. This multiple electrochemical stages are also demonstrated by the ex-situ $\mathrm{XRD}$. The inserted $\mathrm{Al}$ species is clearly exhibited in the form of $\mathrm{Al}$ oxides due to the exposure in ambient environment (Supplementary Fig. S10).

Theoretical capacities of the products are calculated based on the above discussion. As a result, theoretical capacities of $234 \mathrm{mAh} \mathrm{g}^{-1}$ (based on the weight of $\mathrm{Co}_{3} \mathrm{O}_{4}$ and 0.7 mole of Al insertion), $1508 \mathrm{mAh} \mathrm{g}^{-1}$ (based on the weight of $\mathrm{Fe}_{2} \mathrm{O}_{3}$ and 1.5 mole of $\mathrm{Al}$ insertion), and $444 \mathrm{mAh} \mathrm{g}^{-1}$ (based on the weight of $\mathrm{CoFe}_{2} \mathrm{O}_{4}$ and 1.3 mole of $\mathrm{Al}$ insertion) are obtained.

Prior to measuring the capacities of the innovative cathode materials, we test the capacity of naked rGO separately. As depicted in Supplementary Fig. S11, negligibly small capacity values for naked rGO are obtained, ensuring the capacities of the metal-oxide NPs@rGO samples in the subsequent measurements originate from the metal-oxide active materials. Surprisingly, unprecedented high capacity values for $\mathrm{Co}_{3} \mathrm{O}_{4} @ \mathrm{rGO}$ are achieved at a current density of $200 \mathrm{mAg}^{-1}$ (Fig. 6), which should be a favourable breakthrough in the attempt of using metal oxides with heavy electronegative $\mathrm{O}$ ions as cathode materials for AIBs. After the initial activation phase, an AIB with the $\mathrm{Co}_{3} \mathrm{O}_{4} @ \mathrm{rGO}$ cathode material proceeds for 500 cycles with a retained discharge capacity of 168 $\mathrm{mAh} \mathrm{g}^{-1}$ and Coulombic efficiency of $76 \%$ (Fig. 6). Notably, this result is quite superior to that of the previously reported $\mathrm{CuO}$ microspheres and $\mathrm{V}_{2} \mathrm{O}_{5}$ cathode materials in terms of both capacities and lifespan ${ }^{17,19}$. It should be considered that the $\mathrm{Al}$ foil can be directly inserted in an anode side without safety concerns, which is quite different from the conventional Li-ion batteries with a requirement of additional consideration for alternatives to $\mathrm{Li}$ in an anode side. However, The Coulombic efficiencies increase from $60 \%$ to $80 \%$ gradually. This relatively low values suggest remain efforts after the primary demonstration for high potentials of metal oxides as cathode materials for rechargeable aluminum-ion batteries in this report.

Contrary to the $\mathrm{Co}_{3} \mathrm{O}_{4} @ \mathrm{rGO}$, the $\mathrm{Fe}_{2} \mathrm{O}_{3} @ \mathrm{rGO}$ displays inferior capacities of $29 \mathrm{mAh} \mathrm{g}^{-1}$ with a tolerable lifetime (Supplementary Fig. S12a). In addition, $\mathrm{CoFe}_{2} \mathrm{O}_{4} @ \mathrm{rGO}$ shows a high initial discharge capacity of 407 mAh g ${ }^{-1}$ maximum, similar to the $\mathrm{Co}_{3} \mathrm{O}_{4} @ \mathrm{rGO}$ (Supplementary Fig. S12b). However, a rapid decay of capacities for the $\mathrm{CoFe}_{2} \mathrm{O}_{4} @ \mathrm{rGO}$ demonstrates the undesirable electrochemical property. A rational assumption can be due to the deep charge/discharge corresponding to the wide potential range of $0.05-2.2 \mathrm{~V} \mathrm{vs}^{-\mathrm{AlCl}_{4}{ }^{-} / \mathrm{Al} \text {, which }}$ may result in a degradation of polymetallic oxide in $\mathrm{CoFe}_{2} \mathrm{O}_{4} @ \mathrm{rGO}$. We, thus, narrow the potential window from the original range of $0.05-2.2$ to $0.05-1.2 \mathrm{~V}$ vs. $\mathrm{AlCl}_{4}{ }^{-} / \mathrm{Al}$ for further performance analysis. A pair of obvious redox peaks at $\sim 0.5$ (reduction) and $0.9 \mathrm{~V}$ vs. $\mathrm{AlCl}_{4}{ }^{-} / \mathrm{Al}$ (oxidation) are clearly detected in the overlapped (the $1^{\text {st }}$ and $\left.2^{\text {nd }}\right) \mathrm{CV}$ curves for $\mathrm{CoFe}_{2} \mathrm{O}_{4} @ \mathrm{rGO}$ after an activation operation (Fig. 7a). Corresponding redox reactions of the redox peaks are pursued following the same method except that the potential window ranges from 0.05 to $1.2 \mathrm{~V}$ vs. $\mathrm{AlCl}_{4}^{-} / \mathrm{Al}$ without covering the electrochemical reactions at $1.8 / 2.0 \mathrm{~V}$ vs. $\mathrm{AlCl}_{4}{ }^{-} / \mathrm{Al}$ for $\mathrm{CoFe}_{2} \mathrm{O}_{4} @ \mathrm{rGO}$ (Supplementary Eqs S11 and S12). 

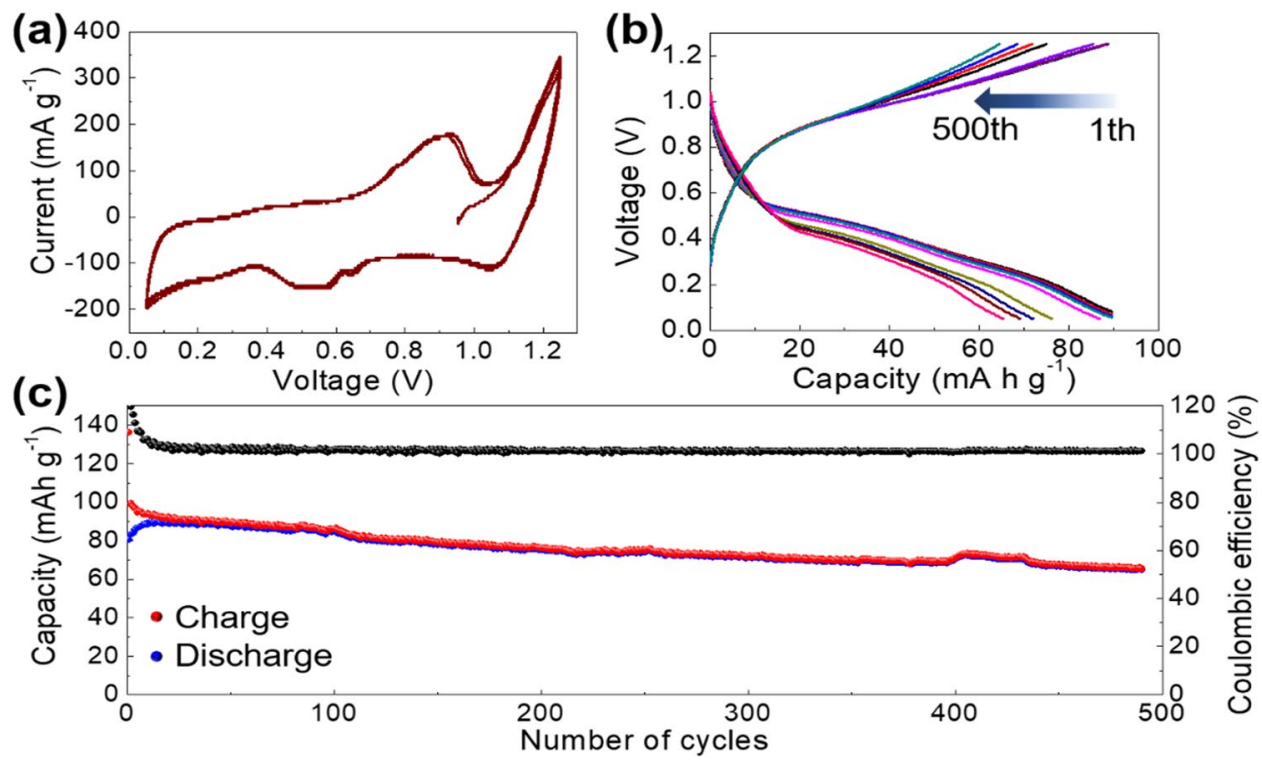

Figure 7. (a) CV curve of the $\mathrm{CoFe}_{2} \mathrm{O}_{4} @ \mathrm{rGO}$ measured within a narrowed potential window of $0.05-1.2 \mathrm{~V}$ vs. $\mathrm{AlCl}_{4}{ }^{-} / \mathrm{Al}$. (b) Representative charge/discharge voltage profiles and (c) capacity values of the $\mathrm{CoFe}_{2} \mathrm{O}_{4} @ \mathrm{rGO}$ for continuous charge/discharge at $1,000 \mathrm{~mA} \mathrm{~g}^{-1}$.

A further long-term charge/discharge demonstration is performed for $\mathrm{CoFe}_{2} \mathrm{O}_{4} @ \mathrm{rGO}$ within the optimized potential window (0.05-1.2 $\mathrm{V} \mathrm{vs}$. $\left.\mathrm{AlCl}_{4}^{-} / \mathrm{Al}\right)$ at a high current density of $1,000 \mathrm{mAg}^{-1}$. A capacity value of $67 \mathrm{mAh}$ $\mathrm{g}^{-1}$ at the $500^{\text {th }}$ charge/discharge cycle is preserved, corresponding to a retention rate of $74 \%$ in comparison with the initial $91 \mathrm{mAh} \mathrm{g}^{-1}$, with a high Coulombic efficiency of $99.6 \%$ (Fig. 7c). Notably, voltage profiles during the charge/discharge proceeding are captured and representatively provided in Fig. 7b, where the undisputed charge/ discharge plateaus are observed at $\sim 0.8$ and $0.4 \mathrm{~V}$ vs. $\mathrm{AlCl}_{4}{ }^{-} / \mathrm{Al}$, suggesting that the $\mathrm{CoFe}_{2} \mathrm{O}_{4} @ \mathrm{rGO}$ is more appropriately used within a shallow charge/discharge range and is a potential cathode material for AIBs.

TEM characterization is further conducted for the samples after repeated charge/discharge cycling tests. The nanoparticles are well trapped inside rGO as depicted in Supplementary Fig. S13. However, decreased crystallinities are observed suggesting the insertion/extraction of charges upon discharge/charge operation which is consistent with the obtained $e x$-situ XRD results where no obvious peaks are detected other than $\mathrm{Al}$ oxides (Supplementary Fig. 10).

Quantitative characterization for the electrochemical impedance of the $\mathrm{CoFe}_{2} \mathrm{O}_{4} @ \mathrm{rGO}$ cathode material is measured using electrochemical impedance spectroscopy (EIS, Supplementary Fig. S14), depicting a depressed semicircle (charge transfer) connected to an oblique line (mass transfer). The EIS curve is studied by incorporating an equivalent circuit (Supplementary Fig. S14 inset). In which, internal resistance $\left(R_{\mathrm{s}}, \sim 40 \Omega\right)$ including electrolyte resistance, electrode resistance, electrode/current collector contact resistance, and current collector resistance is shown. Furthermore, charge transfer resistance $\left(R_{\mathrm{ct}}, \sim 500 \Omega\right)$, Warburg impedance $\left(Z_{\mathrm{w}}\right)$ representing the ionic diffusion resistance, and double layer capacitance $\left(C_{1}\right)$ at the electrode/electrolyte interface are depicted in the EIS curve.

\section{Conclusions}

In this report, we demonstrate high electrochemical activity of economical metal oxides encapsulated in $\mathrm{rGO}$ $\left(\mathrm{Co}_{3} \mathrm{O}_{4} @ \mathrm{rGO}, \mathrm{Fe}_{2} \mathrm{O}_{3} @ \mathrm{rGO}\right.$, and $\left.\mathrm{CoFe}_{2} \mathrm{O}_{4} @ \mathrm{rGO}\right)$ towards Al-ion storage as cathode materials for AIBs. The $\mathrm{Co}_{3} \mathrm{O}_{4} @ \mathrm{rGO}$ displays highly improved electrochemical properties regarding both capacity and lifespan which are superior to the state-of-the-art metal oxide cathode material currently reported by scientific literature. Besides, the $\mathrm{CoFe}_{2} \mathrm{O}_{4} @ \mathrm{rGO}$ exhibits an extremely stable charge/discharge process with a promising Coulombic efficiency of $99.6 \%$ after an optimization for the operating voltage range. This report is expected to stimulate further investigation on metal oxides as economical cathode materials for high performance AIBs.

\section{Methods}

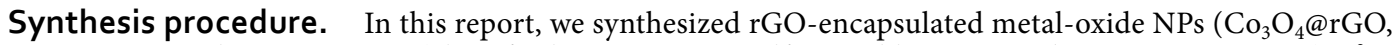
$\mathrm{Fe}_{2} \mathrm{O}_{3} @ \mathrm{rGO}$, and $\left.\mathrm{CoFe}_{2} \mathrm{O}_{4} @ \mathrm{rGO}\right)$ by a facile spontaneous self-assembly process. The MOF precursors $\left(\mathrm{Co}^{2+}-\right.$ hexacyanocobaltate (II), $\mathrm{Fe}^{2+}$-hexacyanoferrate (III), and $\mathrm{Fe}^{2+}$-hexacyanocobaltate (III)) were prepared by a co-precipitation method in aqueous solutions. After a sufficient precipitation reaction, the collected products were rinsed with deionized water several times to remove impure ions from the reactants. The well-cleaned powders were dried in a vacuum oven overnight, ready for the next usage. The metal-oxide NPs were obtained by heating the as-prepared MOF precursors at $700^{\circ} \mathrm{C}$ for $5 \mathrm{~h}$ in air. An aqueous solution comprising of the oxidized metal NPs and polydiallyl dimethyl ammonium chloride (PDDA, $5 \%$ by volume) was prepared. The solution was constantly stirred to uniformly disperse the NPs by surficial electrostatic repulsion. After stirring overnight, the excess PDDA was removed by centrifugation, washing, and re-dispersion in another aqueous solution. 
Afterwards, a diluted graphene suspension $\left(10 \mathrm{~g} \mathrm{~L}^{-1}\right)$ was dropwise added to the metal-oxide NPs suspension under constant stirring. This solution was then constantly stirred for further $24 \mathrm{~h}$. During this period, the metal-oxide NPs would spontaneously attach to and be encapsulated by graphene sheets via electrostatic attraction between the positively charged metal-oxide NPs and the negatively charged graphene sheets. The well-assembled products were filtrated and further annealed at $500{ }^{\circ} \mathrm{C}$ in an argon atmosphere for $2 \mathrm{~h}$.

Characterizations. A structural study was performed via $\mathrm{Cu}-\mathrm{K} \alpha$ radiation equipped XRD (D8-Advance) at a fixed incident angle of $2^{\circ}$, XPS (PHI 5000 VersaProbe) with an Al-Ko source (Sigma probe, VG Scientifics), and Raman spectroscopy (inVia Raman Microscope). Morphologies and constitution elements were demonstrated via SEM (SUPRA 55VP), TEM (JEOL JEM-2100F), EDX mapping, and EPMA. Thermal stability of the as-prepared composites was demonstrated via TGA, which was performed under air flow with temperature ranging from room temperature to $700^{\circ} \mathrm{C}\left(10^{\circ} \mathrm{C} \mathrm{min}^{-1}\right)$. The ratios of $\mathrm{rGO}$ and metal oxides were determined with XRF (ZSX-PRIMUS) technique.

Electrochemical property. The as-prepared samples were manually grinded together with super $\mathrm{P}$ and polyvinylidene fluoride with a weight ratio of 7:2:1; the mixed powders were then dispersed into a constantly stirred $n$-methyl-2-pyrolidinon solution to prepare a uniform slurry for the subsequent electrochemical characterizations. The well-prepared slurry was casted on an organic polymer current collector coated with Pt for conductivity, followed by drying in a vacuum oven overnight to be ready for the subsequent electrochemical measurements.

Electrochemical properties were characterized in pouch cells where the well-dried electrodes were inserted as the cathodes and $\mathrm{Al}$ metal foils $(0.5 \mathrm{~mm})$ were used as anodes. Two pieces of glass-fiber (Whatman) papers soaked with 1-ethyl-3-methylimidazolium chloride ([EMIM]Cl)/ $\mathrm{AlCl}_{3}(1 / 1.3$ molar ratio) were inserted between anodes and cathodes for insulation.

An EIS analysis of the $\mathrm{CoFe}_{2} \mathrm{O}_{4} @ \mathrm{rGO}$ cathode material, after a repeated galvanostatic charge/discharge process for 10 cycles at $100 \mathrm{~mA} \mathrm{~g}^{-1}$, was performed by using the Im6ex ZAHNER. A frequency range used was from $10 \mathrm{mHz}$ to $1 \mathrm{MHz}$, under a constant voltage amplitude of $10 \mathrm{mV}$.

CV measurements were performed on an electrochemical workstation (WBCS3000, Wonatech, Korea) in potential ranges of $0.05-2.2$ and $0.05-1.2 \mathrm{~V}$ vs. $\mathrm{AlCl}_{4}{ }^{-} / \mathrm{Al}$ at a scan rate of $0.5 \mathrm{mV} \mathrm{s}^{-1}$. Galvanostatic charge/discharge cycling measurements were performed within potential windows of $0.05-2.2$ and $0.05-1.2 \mathrm{~V} \mathrm{vs}$. $\mathrm{AlCl}_{4}^{-} /$ $\mathrm{Al}$ at various current densities of 100,200 and 1,000 $\mathrm{mA} \mathrm{g}^{-1}$. Unless otherwise noted, all the current densities and specific capacities in this study were calculated based on the weight of the metal-oxide NP active materials.

Ex-situ characterizations. Pouch cells with electrodes discharged to desired voltages were disassembled, followed by rinsing the cathodes with ethanol and drying in an oven for ex-situ XRD and EDX characterizations.

\section{Data Availability}

The data that support the findings of this study are available from the corresponding authors upon reasonable request.

\section{References}

1. Zhang, K., Varma, R. S., Jang, H. W., Choi, J.-W. \& Shokouhimehr, M. Iron hexacyanocobaltate metal-organic framework: highly reversible and stationary electrode material with rich borders for lithium-ion batteries. J. Alloy Compd. 791, 911-917 (2019).

2. Zhang, K., Lee, T. H., Jang, H. W., Shokouhimehr, M. \& Choi, J.-W. A hybrid energy storage mechanism of zinc hexacyanocobaltatebased metal-organic framework endowing stationary and high-performance lithium-ion storage. Electron. Mater. Lett. 15, 444-453 (2019).

3. Shokouhimehr, M. et al. Metal hexacyanoferrate nanoparticles as electrode materials for lithium ion batteries. Nanosci. Nanotech. Lett. 5, 770-774 (2013).

4. Yu, S.-H., Shokouhimehr, M., Hyeon, T. \& Sung, Y.-E. Iron hexacyanoferrate nanoparticles as cathode materials for lithium and sodium rechargeable batteries. ECS Electrochem. Lett. 2, A39-A41 (2013).

5. Yu, S.-H. et al. Two-dimensional assemblies of ultrathin titanate nanosheets for lithium ion battery anodes. RSC Adv. 4, 12087-12093, https://doi.org/10.1039/c4ra00624k (2014).

6. Zhang, K. et al. Realization of lithium-ion capacitors with enhanced energy density via the use of gadolinium hexacyanocobaltate as a cathode material. ACS Appl. Mater. Inter, https://doi.org/10.1021/acsami.9b07711 (2019).

7. Wang, S. et al. A novel aluminum-ion battery: Al/AlCl ${ }_{3}$ [EMIm] Cl/ $\mathrm{Ni}_{3} \mathrm{~S}_{2} @$ graphene. Adv. Energy Mater. 6, 1600137 (2016).

8. Zhang, Y., Liu, S., Ji, Y., Ma, J. \& Yu, H. Emerging nonaqueous aluminum-ion batteries: challenges, status, and perspectives. Adv. Mater. 30, 1706310 (2018).

9. Lin, M.-C. et al. An ultrafast rechargeable aluminium-ion battery. Nature 520, 324-328 (2015).

10. Wang, H. et al. High-voltage and noncorrosive ionic liquid electrolyte used in rechargeable aluminum battery. ACS Appl. Mater. Inter. 8, 27444-27448 (2016).

11. Liang, K., Ju, L., Koul, S., Kushima, A. \& Yang, Y. Self-supported tin sulfide porous films for flexible aluminum-ion batteries. Adv. Energy Mater. 9, 1802543 (2019).

12. Chen, H. et al. A defect-free principle for advanced graphene cathode of aluminum-ion battery. Adv. Mater. 29, 1605958 (2017).

13. Wu, Y. et al. 3D graphitic foams derived from chloroaluminate anion intercalation for ultrafast aluminum-ion battery. Adv. Mater. 28, 9218-9222 (2016).

14. Wang, D. Y. et al. Advanced rechargeable aluminium ion battery with a high-quality natural graphite cathode. Nat. Commun. 8, 14283, https://doi.org/10.1038/ncomms14283 (2017).

15. Liu, Y. et al. The electrochemical behavior of $\mathrm{Cl}^{-}$assisted $\mathrm{Al}^{3+}$ insertion into titanium dioxide nanotube arrays in aqueous solution for aluminum ion batteries. Electrochim. Acta 143, 340-346 (2014).

16. Lahan, H. \& Das, S. K. Al ${ }^{3+}$ ion intercalation in $\mathrm{MoO}_{3}$ for aqueous aluminum-ion battery. J. Power Sources 413, 134-138 (2019)

17. Wang, H. et al. Binder-free $\mathrm{V}_{2} \mathrm{O}_{5}$ cathode for greener rechargeable aluminum battery. ACS Appl. Mater. Inter. 7, 80-84 (2014).

18. Chiku, M., Takeda, H., Matsumura, S., Higuchi, E. \& Inoue, H. Amorphous vanadium oxide/carbon composite positive electrode for rechargeable aluminum battery. ACS Appl. Mater. Inter. 7, 24385-24389 (2015).

19. Zhang, X., Zhang, G., Wang, S., Li, S. \& Jiao, S. Porous CuO microsphere architectures as high-performance cathode materials for aluminum-ion batteries. J. Mater. Chem. A 6, 3084-3090 (2018). 
20. Zhang, K. et al. Layered metal-organic framework based on tetracycanonickelate as a cathode material for in situ Li-ion storage. RSC Adv. 9, 21363-21370, https://doi.org/10.1039/C9RA03975A (2019).

21. Li, Z., Xiang, K., Xing, W., Carter, W. C. \& Chiang, Y. M. Reversible aluminum-ion intercalation in Prussian blue analogs and demonstration of a high-power aluminum-ion asymmetric capacitor. Adv. Energy Mater. 5, 1401410 (2015).

22. Zhang, K., Lee, T. H., Jang, H. W., Shokouhimehr, M. \& Choi. J.-W. A hybrid energy storage mechanism of zinc hexacyanocobaltatebased metal-organic framework endowing stationary and high-performance lithium-ion storage. Electron. Mater. Lett. 1-10 (2019).

23. Zhang, X. et al. Metal-organic framework derived porous $\mathrm{CuO} / \mathrm{Cu}_{2} \mathrm{O}$ composite hollow octahedrons as high performance anode materials for sodium ion batteries. Chem. Commun. 51, 16413-16416 (2015).

24. Zou, F. et al. Metal organic frameworks derived hierarchical hollow $\mathrm{NiO} / \mathrm{Ni} /$ graphene composites for lithium and sodium storage. ACS Nano 10, 377-386 (2015).

25. Xu, X. et al. A general metal-organic framework (MOF)-derived selenidation strategy for in situ carbon-encapsulated metal selenides as high-rate anodes for Na-ion batteries. Adv. Funct. Mater. 28, 1707573 (2018).

\section{Acknowledgements}

This research was supported by Korea Institute of Science and Technology Future Resource Program (2E29400). Furthermore, the financial supports of the Future Material Discovery Program (2016M3D1A1027666), the Basic Science Research Program (2017R1A2B3009135) through the National Research Foundation of Korea, and China Scholarship Council (201808260042) are appreciated.

\section{Author Contributions}

M.S., J.W.C., M.M. and K.Z. designed and conceived the idea. T.H.L. assisted the transmission electron microscopy characterization. J.H.C. assisted the analyses. H.W.J., J.W.C., M.M. and M.S. developed the project and revised the manuscript. J.W.C., M.M. and M.S. supervised the project. All authors contributed in scientific discussions, experimental studies and preparing the manuscript.

\section{Additional Information}

Supplementary information accompanies this paper at https://doi.org/10.1038/s41598-019-50156-6.

Competing Interests: The authors declare no competing interests.

Publisher's note Springer Nature remains neutral with regard to jurisdictional claims in published maps and institutional affiliations.

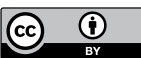

Open Access This article is licensed under a Creative Commons Attribution 4.0 International License, which permits use, sharing, adaptation, distribution and reproduction in any medium or format, as long as you give appropriate credit to the original author(s) and the source, provide a link to the Creative Commons license, and indicate if changes were made. The images or other third party material in this article are included in the article's Creative Commons license, unless indicated otherwise in a credit line to the material. If material is not included in the article's Creative Commons license and your intended use is not permitted by statutory regulation or exceeds the permitted use, you will need to obtain permission directly from the copyright holder. To view a copy of this license, visit http://creativecommons.org/licenses/by/4.0/.

(c) The Author(s) 2019 